\title{
An Australasian Commentary on the AASM Manual for the Scoring of Sleep and Associated Events
}

\author{
Greg Jorgensen ${ }^{1} \cdot$ Carl Downey $^{1} \cdot$ Jeremy Goldin ${ }^{2} \cdot$ Kerri Melehan $^{3} \cdot$ Peter Rochford $^{4} \cdot$ Warren Ruehland $^{4}$ (I)
}

Received: 19 November 2019 / Accepted: 9 February 2020 / Published online: 4 March 2020

(c) The Author(s) 2020

\begin{abstract}
The aim of this document was to provide a commentary on the AASM Manual for Scoring of Sleep and Associated Events in an Australasian context. A panel of Australasian sleep professionals developed the commentary. Each member was tasked with reviewing an assigned section and reporting back with potential AASM Manual clarifications and alterations. These suggestions were evaluated by the panel and ultimately resulted in the recommendations in this document. The panel recognised that the AASM manual significantly advanced the standardisation of polysomnography recording, analysis, and reporting; however, there were sections of the AASM Manual where the panel determined there were clarifications, additions, or alterations required. Some of the key panel recommendations included: (1) advice to exclude arousals in awake epochs in the arousal index, (2) recommendation of a single hypopnoea definition, as well as single options for EEG and EOG placements, (3) a minimum duration for the central and mixed components of a mixed apnoea, (4) the addition of a baseline definition for scoring respiratory events, (5) the addition of criteria for defining oxygen desaturation, and (6) advice change so that the scoring and reporting of respiratory effort-related arousals (RERAs) and snoring is 'recommended' rather than 'optional'. While it is anticipated that the recommendations will improve standardisation across Australasian sleep services many of the recommendations are also relevant in a global setting and should be considered for inclusion in future updates of the AASM Manual.
\end{abstract}

Keywords Polysomnography $\cdot$ American Academy of Sleep Medicine $\cdot$ Sleep $\cdot$ Standards $\cdot$ Scoring

\section{Introduction}

The American Academy of Sleep Medicine Manual for Scoring of Sleep and Related Events (hereafter stated as the AASM Manual) was first published in 2007 [1]. The 2007 AASM Manual retained many core components of the key earlier publications including Rechtschaffen and Kales [2] for sleep staging, the ASDA recommendations for arousals [3] and the AASM 'Chicago Criteria' [4] for respiratory event scoring. This represented the first major effort to develop an integrated and consistent set of scoring rules for

Warren Ruehland

Warren.Ruehland@austin.org.au

1 The Prince Charles Hospital, Chermside, QLD, Australia

2 Royal Melbourne Hospital, Parkville, VIC, Australia

3 Royal Prince Alfred Hospital, Camperdown, NSW, Australia

4 Institute for Breathing and Sleep, Austin Health, Heidelberg, VIC, Australia all events derived from polysomnography (PSG), providing clarifications for the scoring of sleep stages, respiratory events and other sleep-related parameters to improve accuracy and reproducibility in PSG measurement. The recommendations in the 2007 AASM Manual were based on evidence available at the time, and consensus, where evidence was lacking, and was recognised as a step forward in the standardisation of recording, scoring and reporting of PSG [5-7].

The initial Australasian Sleep Association (ASA) and Australasian Sleep Technologists Association (ASTA) combined Commentary, led by Dr Andrew Thornton, was developed and released in 2010 [5] as a response to the 2007 AASM Manual. The goal of the 2010 ASTA/ASA Commentary was to review the 2007 AASM Manual recommendations in light of the established Australasian practices and perspective at the time, while also recognising the need for alignment with a broadly accepted international standard. The 2007 AASM Manual was found to have a number of alternatives, disparities and priorities which in some cases 
had little or no relevance to Australasian patient management practices. If applied without local interpretation it would in some cases affect diagnoses and potential access to treatment. The challenges to local implementation were particularly evident in the classification of respiratory events. The ASTA/ASA Commentary provided additional guidance and clarification to the AASM guidelines which proposed a way forward for Australasian practice consistency.

Since the original release in 2007 there have been several revisions to the AASM Manual. The AASM Manual's first major update, Version 2.0 [8], was published in October 2012 and, in particular, revised respiratory event definitions were included. Subsequent to this, the ASA released the "Guidelines for Sleep Studies in Adults" [9] for Australasian clinicians to progress towards more consistent patient sleep disorder investigation, interpretation, diagnoses, and management practices. The guidelines included the reasonable assumption that the majority of Australian and New Zealand sleep disorder services had moved forward to routinely employ the recommendations of the revised 2012 AASM Manual. There have been further periodic revisions to the 2012 AASM Manual, until the version current at the time of writing, Version 2.6 [10]. In comparison with the 2012 AASM Manual, which included some significant additions and recommendation changes, these revisions listed fewer changes or additions and these were predominantly clarifications with lesser impact on polysomnography scoring.

The aim of the current document is to provide an update to the 2010 ASTA/ASA Commentary [5] by reviewing the most recent AASM Manual (V2.6) [10], and, similar to the 2010 Commentary, to provide recommendations in light of current established Australasian practices and perspective. In doing so, the need for alignment with a broadly accepted international standard was again recognised, and therefore, a goal of this review was to align with the latest AASM Manual wherever possible. In addition to facilitating Australasian practice consistency it was hoped that this review could also provide guidance to future AASM standards.

\section{Materials and methods}

This review and commentary was developed via a collaboration of ASA Clinical Committee members and Australian and New Zealand Sleep Science Association (ANZSSA, formerly ASTA) members. Members of the contributing panel (hereafter referred to as the ASA/ANZSSA Panel) were all service leads with a total of more than 100 years of combined experience in sleep medicine, science and research. This panel first convened in April 2017 at the request of the Clinical Committee of ASA and met by teleconference during 2017 and 2018.
Sections of the AASM Manual were divided between panel members; each member was tasked with reviewing their assigned sections, and reporting back with suggestions for AASM Manual clarifications and alterations. These suggestions were discussed and ultimately resulted in the recommendations that follow in this document.

Although version 2.6 of the AASM Manual [10] was released after this document was submitted and accepted for publication, it was revised to take the minor changes into consideration prior to publication.

\section{Approach and principles}

The general approaches and principles taken by the panel in reviewing the AASM Manual were as follows:

1. Only the ADULT sections of the AASM Manual were considered.

2. A key goal of this review was to align with the latest AASM Manual wherever possible.

3. An important principle and goal of this review was to make a single recommendation without alternatives wherever possible. This principle underpins practice standardisation based on quantifiable and reproducible measurements across services and supports consistent interpretation of disorders identified by polysomnography.

4. This review was considered an update to the 2010 ASTA/ASA commentary, and therefore, recommendations were considered in light of recommendations contained in that commentary.

Recommendations outside or alternate to those of the AASM Manual were derived from consensus after: (1) review of any available evidence and prior recommendations of the 2010 commentary; (2) knowledge and consideration of the reasoning for determinations made by the AASM; (3) consideration of members combined clinical and laboratory experience of variations in service and laboratory practices across Australia and New Zealand; (4) consideration of decisions that may affect patient outcomes and standards of care; and (5) balancing determinations against the need for international standardised practices and measures to facilitate collaborative, comparable research and translation into practice on the broadest scale. Where deviations from the AASM Manual were recommended, explanations were provided.

\section{User guide}

The panel recommend that the AASM Manual, version 2.6 be read and considered in conjunction with this commentary, as the reference and accreditation standard for scoring and reporting sleep investigations performed in Australia and 
New Zealand. If not otherwise stated, the guidelines and recommendations provided in the AASM Manual V2.6 are supported by the panel and should be adhered to.

The AASM Manual identifies RECOMMENDED, ACCEPTABLE and OPTIONAL types of criteria. The panel supports and uses these terms in this document.

The core of this document refers to full laboratory polysomnography. A separate section (IX) in the AASM Manual describes Home Sleep Apnea Testing which in many cases does not align well with portable device monitoring in Australasia. General commentary is included and some recommendations are made in this document, where practices align and where monitoring technology is consistent. As there are significant variations in practice across services based on clinical priorities, equipment variations and other local considerations, not all AASM or ASA/ANZSSA recommendations may be relevant or practical. The ASA/ANZSSA Panel considers that wherever possible, partial monitoring measurement, analysis and reporting should be consistent with this commentary's recommendations.

This commentary aligns with the sections and subsections of the AASM Manual and was considered by the panel as the most efficient way to convey local recommendations without adding additional complication to the interpretation and also to support consistency of practice.

\section{Recommendations}

\section{Parameters to be reported for polysomnography}

The ASA/ANZSSA Panel recommendations relating to Parameters to be Reported for Polysomnography section of the AASM Manual are summarised in Table 1.

\section{A. General parameters}

The ASA/ANZSSA Panel endorse recording and documenting the parameters in the patient report as described in the AASM Manual.

Patient video monitoring and recording The AASM Manual did not identify low-light video monitoring as a General Parameter until version 2.6, however, did identify it within the Technical and Digital Specifications section. In a previous version of this document the ASA/ANZSSA panel recommended the addition of video monitoring as a General Parameter. Video monitoring has considerable value in the identification or exclusion of parasomnia or seizure activity and for unsure event determination [11]. Video monitoring may also be useful in routine polysomnography to verify body or head position which may elucidate positional factors contributing to intermittent sleep-disordered breathing [12] As patient video monitoring is in widespread use during laboratory polysomnography in Australia and New Zealand and provides a valuable adjunct to measurement, reporting and interpretation, its inclusion as a general parameter is supported.

\section{B. Sleep scoring data}

The ASA/ANZSSA Panel endorse reporting the sleep scoring data as described in the AASM Manual.

\section{Arousal events}

The ASA/ANZSSA Panel endorse reporting the number of arousals and the arousal index as described in the AASM Manual.

\section{Cardiac events}

The ASA/ANZSSA Panel endorse reporting the cardiac events as listed in the AASM Manual, with the following alterations:

1. Alter Item D.1 to include average heart rate during wake, in addition to average heart rate during sleep

2. Alter Item D.2 to include lowest heart rate during sleep, in addition to highest heart rate during sleep.

\section{E. Movement events}

Consistent with AASM Manual, the ASA/ANZSSA Panel endorse reporting the number and index of limb movements and limb movements associated with arousal.

\section{F. Respiratory events}

The ASA/ANZSSA Panel agrees with the respiratory event parameters listed as RECOMMENDED and OPTIONAL in the AASM Manual with the following exceptions/additions:

1. Additional AHI/RDI measures (Items F.10 and F.15):

a. Positional AHI/RDI Reporting the RDI/AHI in supine and non-supine positions is RECOMMENDED. Positional sleep apnoea has been estimated to occur in $20-35 \%$ of patients undergoing full-night polysomnography [13] and may influence treatment options [14].

b. Sleep stage specific AHI/RDI Reporting the RDI/ AHI in NREM and REM sleep is RECOMMENDED. REM related OSA has been estimated to have a prevalence of approximately $35 \%$ in clinical OSA populations [15] and although REM-related 
Table 1 Summary of alterations to the AASM Manual Parameters to be Reported recommended by the ASA/ANZSSA Panel

\begin{tabular}{|c|c|c|c|}
\hline II. Parameters to be reported for polysomnography & AASM & ANZSSA/ASA & Difference \\
\hline \multicolumn{4}{|l|}{ A. General parameters } \\
\hline Items $1-10$ & & & No change \\
\hline \multicolumn{4}{|l|}{ B. Sleep scoring data } \\
\hline Items $1-10$, note 1 & & & No change \\
\hline \multicolumn{4}{|l|}{ C. Arousal events } \\
\hline Items $1-2$ & & & No change \\
\hline \multicolumn{4}{|l|}{ D. Cardiac events } \\
\hline Item 1. Average heart rate during sleep and awake & RECOMMENDED & RECOMMENDED & Change \\
\hline Item 2. Highest and lowest heart rate during sleep & RECOMMENDED & RECOMMENDED & Change \\
\hline Items $3-10$ & & & No change \\
\hline \multicolumn{4}{|l|}{ E. Movement events } \\
\hline Items $1-5$, Note 1 & & & No change \\
\hline \multicolumn{4}{|l|}{ F. Respiratory events } \\
\hline Items $1-9,11-12,19,22,24$, Notes $1-2,5$ & & & No change \\
\hline Item 10. Apnoea-Hypopnoea Index (AHI) & RECOMMENDED & RECOMMENDED & No change \\
\hline a. AHI in supine and non-supine sleep & Not Included & RECOMMENDED & Addition \\
\hline b. AHI in NREM and REM sleep stages & Not Included & RECOMMENDED & Addition \\
\hline c. AHI at treatment levels & Not included & OPTIONAL & Addition \\
\hline Item 13. Number of respiratory effort related arousals & OPTIONAL & RECOMMENDED & Advice change \\
\hline Item 14. Respiratory effort related arousal index & OPTIONAL & RECOMMENDED & Advice change \\
\hline Item 15. Respiratory disturbance index (RDI) & OPTIONAL & RECOMMENDED & Advice change \\
\hline a. RDI in supine and non-supine sleep & Not Included & RECOMMENDED & Addition \\
\hline b. RDI in NREM and REM sleep stages & Not Included & RECOMMENDED & Addition \\
\hline c. RDI at treatment levels & Not included & OPTIONAL & Addition \\
\hline \multicolumn{4}{|l|}{ Item 16. Number of oxygen desaturations } \\
\hline a. Number of oxygen desaturations of $\geq 3 \%$ & OPTIONAL & RECOMMENDED & Advice change \\
\hline b. Number of oxygen desaturations $\geq 4 \%$ or other threshold & OPTIONAL & OPTIONAL & No change \\
\hline \multicolumn{4}{|l|}{ Item 17. Oxygen desaturation index } \\
\hline a. Oxygen desaturation index of $\geq 3 \%$ & OPTIONAL & RECOMMENDED & Advice change \\
\hline b. Oxygen desaturation index of $\geq 4 \%$ or other threshold & OPTIONAL & OPTIONAL & No change \\
\hline \multicolumn{4}{|l|}{ Item 18. Arterial oxygen saturation } \\
\hline a. Mean value & RECOMMENDED & & \\
\hline i. Mean stable baseline prior to sleep onset & Not Included & RECOMMENDED & Addition \\
\hline ii. Mean during stable NREM sleep & Not Included & RECOMMENDED & Addition \\
\hline b. Duration and/or percentage of sleep time $\leq 88 \%$ & OPTIONAL* & RECOMMENDED & Advice change \\
\hline $\begin{array}{l}\text { Item 20. If electing to measure arterial } \mathrm{pCO}_{2} \text { or surrogate during diagnostic or } \\
\text { PAP titration (adults): }\end{array}$ & & & Wording change \\
\hline a. Occurrence of hypoventilation & RECOMMENDED $\dagger$ & RECOMMENDED & No change \\
\hline b. Baseline value prior to sleep onset & Not included & RECOMMENDED & Addition \\
\hline c. Maximum value in NREM and REM & Not included & RECOMMENDED & Addition \\
\hline d. Maximum value at treatment levels & Not included & OPTIONAL & Addition \\
\hline e. Average value after sleep offset & Not included & OPTIONAL & Addition \\
\hline Item 21. Occurrence of hypoventilation during PAP titration (adults): & OPTIONAL & Moved to Item 20 & Deletion \\
\hline $\begin{array}{l}\text { Item 23. Duration of Cheyne-Stokes breathing or the number of Cheyne-Stokes } \\
\text { breathing events }\end{array}$ & RECOMMENDED & OPTIONAL & Advice change \\
\hline Item 25. Occurrence of snoring & OPTIONAL & RECOMMENDED & Advice change \\
\hline Item 26. If arterial blood gasses (ABGs) are taken: & & & Addition \\
\hline a. Time of day sample collected & Not included & RECOMMENDED & Addition \\
\hline b. Measurement conditions: Room air, supplemental $\mathrm{O}_{2}$, or treatment & Not included & RECOMMENDED & Addition \\
\hline c. Report pH, $\mathrm{PaO}_{2}, \mathrm{PaCO}_{2}, \mathrm{HCO}_{3-}, \mathrm{BE}, \mathrm{SaO}_{2}$ & Not included & RECOMMENDED & Addition \\
\hline
\end{tabular}


Table 1 (continued)

\begin{tabular}{|c|c|c|c|}
\hline II. Parameters to be reported for polysomnography & AASM & ANZSSA/ASA & Difference \\
\hline $\begin{array}{l}\text { Note 3: Percent of sleep time below threshold of oxygen saturation may be } \\
\text { reported at the discretion of the clinician (other than } \leq 88 \% \text { which is RECOM- } \\
\text { MENDED; see item 18) }\end{array}$ & & & Change \\
\hline Note 4: Reporting hypoventilation [this note incorporated into Item 20] & & & Deleted \\
\hline \multicolumn{4}{|l|}{ G. Summary Statements } \\
\hline Items $1-4$ & & & No change \\
\hline Item 5. A graphical summary of the recording including: & & & Change \\
\hline a. Sleep hypnogram, & OPTIONAL & RECOMMENDED & Advice change \\
\hline $\begin{array}{l}\text { b. Time/epoch, } \mathrm{SpO}_{2}, \mathrm{TcCO}_{2} \text { (if recorded), body position, respiratory event } \\
\text { occurrence, arousal occurrence, limb movement occurrence, heart rate, treat- } \\
\text { ment levels (if any) }\end{array}$ & Not included & RECOMMENDED & Addition \\
\hline \multicolumn{4}{|l|}{ Item 6. For treatment studies } \\
\hline a. Therapy equipment trialled & Not included & RECOMMENDED & Addition \\
\hline b. Most effective equipment and treatment parameters & Not included & RECOMMENDED & Addition \\
\hline c. Other treatment conditions, e.g., supplemental $\mathrm{O}_{2}$, MAS, positional device & Not included & RECOMMENDED & Addition \\
\hline $\begin{array}{l}\text { Item 7. Clinical and technical observations that may impact interpretation of the } \\
\text { investigation }\end{array}$ & Not included & RECOMMENDED & Addition \\
\hline $\begin{array}{l}\text { Item 8. A statement clarifying scoring and analysis criteria used, e.g., AASM, } \\
\text { ASA/ANZSSA specific publication or any deviation }\end{array}$ & Not included & RECOMMENDED & Addition \\
\hline $\begin{array}{l}\text { Item } 9 \text {. A record of patient perception of sleep quality during the investigation } \\
\text { compared to their usual sleep quality }\end{array}$ & Not included & RECOMMENDED & Addition \\
\hline H. Identifiers & Not included & RECOMMENDED & Addition \\
\hline $\begin{array}{l}\text { Item } 1 \text {. Identification of the sleep service performing the investigation and its } \\
\text { parent organisation }\end{array}$ & Not included & RECOMMENDED & Addition \\
\hline $\begin{array}{l}\text { Item } 2 \text {. A minimum of three patient identifiers (e.g., name, date of birth, medical } \\
\text { record number) }\end{array}$ & Not included & RECOMMENDED & Addition \\
\hline Item 3. Dates of investigation, analysis and reporting & Not included & RECOMMENDED & Addition \\
\hline Item 4. Investigation type (Diagnostic, CPAP titration, CPAP review, etc.). & Not included & RECOMMENDED & Addition \\
\hline $\begin{array}{l}\text { Item 5. Identification of the reporting physician on the PSG report and any cor- } \\
\text { respondence, referral or treatment prescription }\end{array}$ & Not included & RECOMMENDED & Addition \\
\hline
\end{tabular}

*This Item OPTIONAL in note 3

†This Item RECOMMENDED in note 4

OSA may result in a low overall AHI/RDI, it may warrant treatment [16].

c. Treatment AHI/RDI Reporting the RDI/AHI at different treatment levels is OPTIONAL.

2. Respiratory effort-related arousals (Items F.13-14) Reporting the number/index of respiratory effortrelated arousals (RERAs) is OPTIONAL according to the AASM Manual but is RECOMMENDED by the ASA/ANZSSA Panel. Although the AASM note that the evidence for the clinical utility of reporting RERAs is limited and that there are fewer RERAs scored when using a hypopnoea definition allowing for an associated arousal $[17,18]$, it remains possible that RERAs may be more important for some individuals; more so in lean individuals and women $[19,20]$. RERAs were considered by consensus to provide significant additional information on event contribution to sleep fragmentation and identification of otherwise unclassified respiratory events as an aid to interpretation.

3. Oxygen saturation and desaturation (Items F.16-18) Reporting the number/index of oxygen desaturations is OPTIONAL according to the AASM Manual but is RECOMMENDED by the ASA/ANZSSA Panel. The ODI is relatively simple to calculate and, as suggested by the AASM [18], it may provide additional information when using a hypopnoea criteria allowing arousal. To standardise reporting, and as suggested by the AASM manual supporting article [18], the Oxygen Desaturation Index (ODI) should identify $\geq 3 \%$ oxygen desaturations (i.e., in accordance with scoring hypopnoeas: VIII. Respiratory Rules, Section D.1A.). Additional desaturation indices may be required by some services for clinical decisions and local policies such as access to home oxygen. The desaturation criteria must be stated (e.g., $\geq 3 \%$ or $4 \%$ ). The duration and/or a percentage of sleep or 
recording time with $\mathrm{SpO}_{2} \leq 88 \%$ is RECOMMENDED to be reported to be consistent with Thoracic Society of Australia and New Zealand (TSANZ) nocturnal oxygen requirement guidelines [21]. A service may also elect to report on the time and/or proportion of sleep with $\mathrm{SpO}_{2}<90 \%$ or other thresholds at their discretion. The AASM Manual recommends reporting the mean oxygen saturation but does not specify whether the mean value should be recorded during awake or asleep. Reporting (1) the average awake $\mathrm{SpO}_{2}$ stable baseline prior to sleep onset, and (2) the average during stable NREM sleep (if recorded), is RECOMMENDED.

4. Occurrence of hypoventilation and $\mathrm{TcCO}_{2}$ (Items F.20-21) If electing to measure arterial $\mathrm{pCO}_{2}$ or surrogate (e.g., transcutaneous carbon dioxide partial pressure $\left(\mathrm{TcCO}_{2}\right)$ ) during polysomnography, the presence/ absence of hypoventilation is RECOMMENDED to be included in the PSG report (as per Note 4 of the AASM Manual). In addition it is RECOMMENDED the average wake $\mathrm{TcCO}_{2}$ (or equivalent) stable baseline prior to sleep onset, and the maximum value in REM and NREM sleep should also be reported. Recording the maximum value at treatment levels is considered OPTIONAL. Recording the average wake $\mathrm{TcCO}_{2}$ in the morning after sleep offset to identify any persistent change in $\mathrm{TcCO}_{2}$ (which may be due to continuing hypoventilation and/or electrode calibration drift) is OPTIONAL yet desirable. The ASA/ANZSSA Panel recommends that monitoring continues post wakefulness until return to a stable measurement is recognised.

5. Cheyne-Stokes respiration (Items F.22-23) A measure of the duration of Cheyne-Stokes breathing or number of Cheyne-Stokes breathing events is RECOM$M E N D E D$ in the AASM Manual. The clinical utility of reporting these statistics is yet to be established; therefore, the ASA/ANZSSA Panel consensus was that these should be OPTIONAL reporting parameters. Reporting the presence of Cheyne-Stokes breathing in the report is RECOMMENDED.

6. Occurrence of snoring (Item F.25) Reporting the occurrence of snoring is OPTIONAL according to the AASM Manual but is RECOMMENDED by the ASA/ANZSSA Panel. As per VIII. Respiratory Rules, A. Technical Specifications in this document, to standardise the recording of snoring the panel recommend the use of a sound level meter. Reporting the maximum level of snoring sound during the investigation (in $\mathrm{dB}$ if employing a sound level meter), with identification of the patient position and sleep stage at the time, is RECOMMENDED. Snoring is a common complaint in clinical populations, however, may be underreported, particularly in females [22]. Similar to the reporting of RERAs and the ODI the panel consensus is that these snoring inclusions suf- ficiently aid clinical interpretation and recording measurement standards.

7. Arterial blood gases (Additional Item 26) If arterial blood gases (ABGs) are measured in conjunction with the investigation, reporting the following parameters is RECOMMENDED:

- Time of day the sample was collected

- Measurement conditions: room air, supplemental $\mathrm{O}_{2}$ $\left(\mathrm{L} / \mathrm{min}\right.$ or $\left.\mathrm{FiO}_{2}\right)$

- Treatment or interventions that may influence the patient's ventilation (e.g. CPAP, NIV)

- Reporting of $\mathrm{pH}, \mathrm{PaO}_{2}, \mathrm{PaCO}_{2}, \mathrm{HCO}_{3-}, \mathrm{BE}$ and $\mathrm{SaO}_{2}$.

ABGs may be a useful adjunct to $\mathrm{TcCO}_{2}$ monitoring. $\mathrm{ABG}$ sampling and a simultaneous $\mathrm{TcCO}_{2}$ reading taken prior to Lights Off allows $\mathrm{TcCO}_{2}$ values throughout the PSG to be aligned more closely to arterial values through the use of equipment correction options. A second $\mathrm{ABG}$ and simultaneous $\mathrm{TcCO}_{2}$ reading taken as soon as possible after Lights On allows estimation of the magnitude of any $\mathrm{TcCO}_{2}$ calibration drift recorded [23].

\section{G. Summary statements}

The ASA/ANZSSA Panel endorses the Summary Statements in the AASM Manual with the following exceptions/ additions:

1. Hypnogram (Item G.5) A sleep hypnogram is listed as OPTIONAL in the AASM Manual but is RECOMMENDED by the ASA/ANZSSA Panel. Additionally, it is RECOMMENDED that the hypnogram be incorporated into a graphical representation of the entire investigation displaying the following additional features: time/epoch, body position, $\mathrm{SpO}_{2}, \mathrm{TcCO}_{2}$ if recorded, respiratory event occurrence, arousal occurrence, limb movement occurrence, heart rate, and treatment levels (if any).

2. Treatment (Additional Item G.6) If a treatment study is undertaken, reporting the following parameters is RECOMMENDED:

- Treatment type, device, mode, interface and therapeutic settings trialled

- The most effective equipment and treatment parameters

- Other treatment conditions e.g., supplemental $\mathrm{O}_{2}$, MAS, positional devices etc. 
3. Other statements (additional Items G.7, 8 and 9) Inclusion of the following parameters in the report is also RECOMMENDED:

- Clinical and technical observations that may impact interpretation of the investigation

- A statement clarifying scoring and analysis criteria used, e.g., AASM, ASA/ANZSSA specific publication or any deviation

- A record of patient perception of sleep quality during the investigation compared to their usual sleep quality

\section{H. Identifiers (additional section)}

Inclusion of the following parameters and service identifiers in the report is RECOMMENDED:

1. Identification of the sleep service performing the investigation and its parent organisation

2. A minimum of three patient identifiers (e.g., name, date of birth, medical record number)
3. Dates of investigation, analysis and reporting for quality management review

4. Investigation type (e.g., Diagnostic, CPAP titration, CPAP review, etc.).

5. Identification of the reporting physician.

\section{Technical and digital specifications}

The ASA/ANZSSA Panel recommendations relating to the Technical and Digital Specifications section of the AASM Manual are summarised in Table 2.

\section{A. Digital specifications for routine PSG recordings}

Sampling rates (Item A.3) The ASA/ANZSSA Panel recommend using no less than the minimum sampling rates listed; however, there may be additional recording requirements, where higher sampling rates should be considered to retain sufficient recording resolution. Note that adequate signal resolution requires sampling rates be at least twice the expected frequency of the event to be recorded [24]. Alterations/additions to this section include:

Table 2 Summary of alterations to the AASM Manual Technical Specifications recommended by the ASA/ANZSSA Panel

III. Technical and digital specifications

\begin{tabular}{|c|c|c|c|}
\hline & AASM & ANZSSA/ASA & Difference \\
\hline \multicolumn{4}{|l|}{ A. Digital Specifications for Routine PSG recordings } \\
\hline Items $1-2,4$, Notes $1-8,10-14$ & & & No change \\
\hline \multicolumn{4}{|l|}{ Item 3. Sampling Rates } \\
\hline a. Currently listed channels (EEG, EOG, etc.) & RECOMMENDED & RECOMMENDED & No change \\
\hline b. PAP pressure and Leak: Minimal $10 \mathrm{~Hz}$ & Not included & RECOMMENDED & Addition \\
\hline c. Digital video: 1 frame/s & Not included* & RECOMMENDED & Addition \\
\hline $\begin{array}{l}\text { Note 9: Nasal pressure and PAP flow recordings should use sampling rates higher } \\
\text { than the proposed sampling rate if snoring is to be measured on these channels } \\
\text { [See note 11]. }\end{array}$ & & & Change to note \\
\hline $\begin{array}{l}\text { Note } 15 \text { : If it is evident that mains power interference is compromising signal qual- } \\
\text { ity the addition of a notch filter set at } 50 \mathrm{~Hz} \text { is recommended }\end{array}$ & & & Additional note \\
\hline \multicolumn{4}{|l|}{ B. PSG recording features } \\
\hline Items $1-8$ & & & No change \\
\hline \multicolumn{4}{|l|}{ C. Use systems with the following PSG display and display manipulation features } \\
\hline Items $1-10$ & & & No change \\
\hline $\begin{array}{l}\text { Item } 11 \text {. Channel display size and horizontal and vertical data window size should } \\
\text { be standardised within a service to ensure amplitude dependent decisions (e.g., } \\
\text { EEG, EOG) are consistently applied. Sleep staging should be undertaken with } \\
\text { EEG and EOG channels displayed with a scale of } 1 \mathrm{~s} / \mathrm{cm} \text { horizontal rate and } \\
100 \mathrm{uV} / \mathrm{cm} \text { deflection within the channel montage recorded. }\end{array}$ & Not included & RECOMMENDED & Additional item \\
\hline \multicolumn{4}{|l|}{ D. Perform the Following Digital Analyses of PSG } \\
\hline Items $1-4$ & & & No change \\
\hline \multicolumn{4}{|l|}{ E. Perform the following calibrations to document appropriate system response } \\
\hline Items $1-20$ and Notes $1-11$ & & & No change \\
\hline Item 21. Repeat physiological calibrations at the end of the PSG recording & RECOMMENDED & OPTIONAL & Advice change \\
\hline
\end{tabular}

*Noted in section C. Item 4 
1. In addition to the parameters listed in the AASM Manual, the ASA/ANZSSA Panel recommend the minimum sampling rates for the following parameters for positive airway pressure (PAP) treatment studies:

i. Pressure $10 \mathrm{~Hz}$.

ii. Leak $10 \mathrm{~Hz}$.

2. The ASA/ANZSSA Panel recommend nasal pressure and PAP flow recordings use sampling rates higher than the proposed sampling rate if snoring is to be measured on these channels (change to note 9).

Routinely recorded filter settings (Item A.4) The ASA/ ANZSSA Panel recommend using the low and high frequency digital filter settings listed in the AASM Manual, with the addition of a notch filter set at $50 \mathrm{~Hz}$ if it is evident that mains power interference is compromising signal quality.

\section{B. PSG recording features}

The ASA/ANZSSA Panel endorses the PSG recording features as listed in the AASM Manual.

\section{Use systems with the following PSG display and display manipulation features}

The ASA/ANZSSA Panel consider using display specifications as listed in the AASM Manual as an absolute minimum. Note that while the AASM Manual recommends a minimum screen size and resolution, the panel considered it inadequate to standardise signal display. The ASA/ANZSSA Panel recommend channel display size and horizontal and vertical data window size are held consistent within a service to ensure amplitude dependent decisions (e.g., EEG, EOG) are consistently applied. Sleep staging should be undertaken with a monitor and data windows which can display EEG and EOG channels of $1 \mathrm{~s} / \mathrm{cm}$ horizontal rate and $100 \mu \mathrm{V} / \mathrm{cm}$ deflection within the channel montage recorded. The size of the monitor and window must also be in proportion to adequately display all channels recorded to easily identify criteria recommended in this commentary.

\section{Perform the following digital analyses of PSG}

The ASA/ANZSSA Panel endorses using digital analysis features as listed in the AASM Manual.

\section{E. Perform the following calibrations to document appropriate system response}

The ASA/ANZSSA Panel recommend undertaking the calibrations listed in the AASM Manual at the beginning of each attended sleep investigation and permanently recorded with the PSG. Although signal calibrations at the end of the study may be beneficial to assure signal quality, they can be impractical in routine practice for scientific staff and the patient, and not of sufficient value to be considered mandatory.

\section{Sleep staging rules}

The ASA/ANZSSA Panel recommendations relating to the Sleep Staging Rules section of the AASM Manual are summarised in Table 3.

The underlying rules and definitions for sleep stage scoring remain largely unchanged in the AASM Manual from 2007; however, major revisions to the wording of these sections were undertaken in 2012 for added clarity, with further minor revisions of the text in subsequent versions. Thus the ASA/ANZSSA Panel accepts the majority of the AASM recommendations. The only departures are as follows:

\section{A. Technical specifications for electroencephalogram (EEG)}

The ASA/ANZSSA Panel agrees with the RECOMMENDED EEG derivations as described in the AASM Manual. As noted in the previous ASTA/ASA $2010 \mathrm{Com}-$ mentary, the ACCEPTABLE EEG placements at $\mathrm{Fz}-\mathrm{Cz}$, $\mathrm{Cz}-\mathrm{Oz}$ described in the AASM Manual were not considered to provide any significant advantage, and evidence to support these placements is limited, and therefore, they are not recommended in routine practice.

\section{B. Technical specifications for electrooculogram (EOG)}

The ASA/ANZSSA Panel endorse the RECOMMENDED EOG derivations and electrode placements as described in the AASM Manual (E1-M2; E2-M2) including referencing E1 and E2 to M1 if the M2 reference should fail. As noted in the previous ASA/ASTA 2010 Commentary, the AASM Manual identified the EOG derivation of E1 and E2 one centimetre below and lateral to each outer canthus with a reference electrode at Fpz as ACCEPTABLE practice, however, not offering any explanation of significant clinical advantage, and as such, this is not recommended in routine practice. 
Table 3 Summary of alterations to the AASM Manual Sleep Staging Rules recommended by the ASA/ANZSSA Panel

IV. Sleep staging rules

\begin{tabular}{|c|c|c|c|}
\hline & AASM & ANZSSA/ASA & Difference \\
\hline \multicolumn{4}{|l|}{ A. Technical specifications for electroencephalogram (EEG) } \\
\hline Item 1,3 , Notes $1-2$ & & & No change \\
\hline Item 2. Acceptable EEG derivations ( $\mathrm{Fz}-\mathrm{Cz}, \mathrm{Cz}-\mathrm{Oz}, \mathrm{C} 4-\mathrm{M} 1)$ & ACCEPTABLE & Not recommended & Advice change \\
\hline $\begin{array}{l}\text { Note 3: EEG amplitude For measuring the amplitude of frontal activity for determina- } \\
\text { tion of slow wave activity use frontal EEG leads }\end{array}$ & & & $\begin{array}{l}\text { Delete reference } \\
\text { to acceptable } \\
\text { EEG }\end{array}$ \\
\hline \multicolumn{4}{|l|}{ B. Technical specifications for electrooculogram (EOG) } \\
\hline Item 1 , Note 1 & & & No change \\
\hline Item 2. Acceptable EOG derivations (E1-Fpz, E2-Fpz) & ACCEPTABLE & Not recommended & Advice change \\
\hline $\begin{array}{l}\text { Note 2: EOG deflections When using the recommended EOG derivations, conjugate } \\
\text { eye movements result in out-of-phase deflections }\end{array}$ & & & $\begin{array}{l}\text { Delete reference } \\
\text { to acceptable } \\
\text { EOG }\end{array}$ \\
\hline \multicolumn{4}{|l|}{ C. Technical specifications for electromyogram (EMG) } \\
\hline Items $1-2$, Note 1 & & & No change \\
\hline \multicolumn{4}{|l|}{ D. General Scoring of Sleep Stages } \\
\hline Items $1-3$, Note 1 & & & No change \\
\hline \multicolumn{4}{|l|}{ E. Scoring Stage W } \\
\hline Items $1-2$, Notes $1-5$ & & & No change \\
\hline \multicolumn{4}{|l|}{ F. Scoring Stage N1 } \\
\hline Items $1-6$, Notes $1-5$ & & & No change \\
\hline \multicolumn{4}{|l|}{ G. Scoring Stage N2 } \\
\hline Items $1-6$, Notes $1-6$ & & & No change \\
\hline \multicolumn{4}{|l|}{ H. Scoring Stage N3 } \\
\hline Items $1-2$, Notes $1-6$ & & & No change \\
\hline \multicolumn{4}{|l|}{ I. Scoring Stage R } \\
\hline Items $1-5,6 a-b, 6 d-e, 7$, Notes $1-6$ & & & No change \\
\hline $\begin{array}{l}\text { Item 6c. End scoring of Stage } R \text { When an arousal interrupts Stage } \mathrm{R} \text { and is followed by } \\
\text { slow eye movements AND a low-amplitude mixed-frequency EEG without posterior } \\
\text { dominant rhythm, score the portion of the record containing the slow eye movements } \\
\text { as Stage N1 even if the chin EMG activity remains low (at Stage R level). [Remain- } \\
\text { der of note unchanged]. }\end{array}$ & & & Wording change \\
\hline \multicolumn{4}{|l|}{ J. Scoring epochs with major body movements } \\
\hline Items $1-4$ & & & No change \\
\hline
\end{tabular}

\section{Scoring stage $R$}

In version 2.6 of the AASM Manual Rule 6c and Fig. 15 were updated to specify what happens after an arousal interrupts stage $\mathrm{R}$. While the intention of the update is clear Item 6c remains poorly worded. Instead of, "When an arousal interrupts Stage $\mathrm{R}$ and is followed by a low-amplitude mixed-frequency EEG without posterior dominant rhythm AND slow eye movements ..." [Emphasis from AASM Manual] for clarity it should state, "When an arousal interrupts Stage R and is followed by slow eye movements AND a low-amplitude mixed-frequency EEG without posterior dominant rhythm ...".

\section{Arousal rule}

The ASA/ANZSSA Panel recommendations relating to the Arousal Rule section of the AASM Manual are summarised in Table 4.

The ASA/ANZSSA Panel recommends the rule for the scoring of arousals as described in the AASM Manual with the following clarifications and deviations:

1. Arousals in wake epochs (Note 3) Arousals meeting AASM scoring criteria and occurring entirely during an epoch scored wake during the recorded time should be scored in accordance with the AASM Manual RECOMMENDED criteria, however, in keeping with the conclusion detailed in the 2010 ASTA/ASA Commentary, it is 
Table 4 Summary of alterations to the AASM Manual Arousal Rules recommended by the ASA/ANZSSA Panel

\begin{tabular}{|c|c|c|c|}
\hline \multicolumn{4}{|l|}{ V. Arousal rules } \\
\hline & AASM & ANZSSA/ASA & Difference \\
\hline \multicolumn{4}{|l|}{ A. Scoring arousals } \\
\hline Items 1 , Notes $1-2$ and $4-5$ & & & No change \\
\hline $\begin{array}{l}\text { Note 3: Scoring arousals in awake epochs Arousals meeting all scoring criteria but occurring } \\
\text { entirely during an awake epoch in the recorded time between "lights out" and "lights on" } \\
\text { should be scored but not used for computation of the arousal index }\end{array}$ & & & Change \\
\hline $\begin{array}{l}\text { Item 2: Arousal classification The following criteria should be applied to classify arousal } \\
\text { types: }\end{array}$ & Not included & RECOMMENDED & Addition \\
\hline \multicolumn{4}{|l|}{$\begin{array}{l}\text { a. Respiratory arousal scored when the arousal occurs less than } 5 \mathrm{~s} \text { after the termination of a } \\
\text { scored respiratory event (other than during periodic breathing - see Note } 7 \text { below). }\end{array}$} \\
\hline \multicolumn{4}{|l|}{$\begin{array}{l}\text { b. Limb movement arousal Scored when there is an overlap of the events (arousal and limb } \\
\text { movement) or when there is }<0.5 \mathrm{~s} \text { between the end of one event and the onset of the other } \\
\text { event irrespective of which event occurs first. }\end{array}$} \\
\hline \multicolumn{4}{|l|}{ c. Spontaneous arousal An arousal not meeting one of the above associations } \\
\hline $\begin{array}{l}\text { Note 6: If an arousal meets both respiratory and limb movement association rules, a respira- } \\
\text { tory arousal should be scored. }\end{array}$ & & & Addition \\
\hline $\begin{array}{l}\text { Note 7: Arousals which occur during the hyperpnoea phase within a periodic breathing pat- } \\
\text { tern, e.g., Cheyne-Stokes respiration, should be scored as respiratory arousals }\end{array}$ & & & Addition \\
\hline
\end{tabular}

RECOMMENDED they not be used in the computation of the arousal index.

In keeping with the earlier 2010 Commentary and the current AASM rule for handling respiratory events scored in wake epochs, arousals where any portion of the arousal crosses into an epoch marked as sleep should be included in the arousal index.

Since arousals entirely in wake epochs are scored, a laboratory that has a particular need to calculate the arousal index in keeping with the AASM Manual may readily do so.

Although this recommendation will likely have minimal impact on investigation interpretation, the ASA/ ANZSSA Panel had considerable discussion around it, which highlighted limitations of the historical use of standard epochs. See the Discussion for details of these considerations. The rationale for departure from the AASM Manual relates to the internal contradiction arising from the counting arousals in awake and sleep epochs, and dividing only by the sleep time.

2. Arousal classification (Additional Item 2) Classification of arousals is considered by panel consensus to provide sufficient additional clinical information on the source of arousal and is, therefore, RECOMMENDED. The distribution of arousal count/index between different sleep stages may also aid clinical interpretation in specific investigations, and is considered OPTIONAL. Apply the following criteria to classify arousal types:
- Respiratory arousal Scored when the arousal occurs less than $5 \mathrm{~s}$ after the termination of a scored respiratory event (other than during periodic breathingsee below).

- Limb movement arousal Scored when there is an overlap of the arousal and limb movement or when there is $<0.5 \mathrm{~s}$ between the end of one event and the onset of the other event irrespective of which event (arousal or limb movement) occurs first.

- Spontaneous arousal Arousal not meeting one of the above associations.

Notes:

1. Additional Note 6 If an arousal meets both respiratory and limb movement association rules, a respiratory arousal should be scored.

2. Additional Note 7 Arousals which occur during the hyperpnoea phase within a periodic breathing pattern (e.g., Cheyne-Stokes respiration), should be scored as respiratory arousals.

\section{Cardiac rules}

The ASA/ANZSSA Panel recommendations relating to the Cardiac Rules section of the AASM Manual are summarised in Table 5.

\section{A. Technical specifications}

The ASA/ANZSSA Panel endorse the technical specifications as listed in the AASM Manual. 
Table 5 Summary of alterations to the AASM Manual Cardiac Rules recommended by the ASA/ANZSSA Panel

\begin{tabular}{llll}
\hline VI. Cardiac rules & & & ANZSSA/ASA \\
\hline & AASM & & Difference \\
\hline A. Technical specifications & & & No change \\
Item 1, Notes 1-4 & & OPTIONAL & Advice change \\
B. Scoring cardiac events & RECOMMENDED & No change \\
Items 1-6 & & &
\end{tabular}

\section{B. Scoring cardiac events}

Accurate routine scoring of cardiac abnormalities and events would be desirable; however, significant practical and technical limitations and availability of support software limit the majority of sleep laboratories to provide a detailed analysis.

The identification of each episode of cardiac arrhythmia is therefore considered OPTIONAL by this panel, as counting or reporting an index of these events is not routinely undertaken in Australasian laboratories.

Cardiac abnormalities identified are better characterised by cardiac specialty services; however, inclusion of a description of the presence and characteristics of cardiac abnormalities in the laboratory report is RECOMMENDED.

\section{Movement rules}

The ASA/ANZSSA Panel recommendations relating to the Movement Rules section of the AASM Manual are summarised in Table 6.

The ASA/ANZSSA panel largely supports the Movement Rule technical specifications, definitions and rules as listed in the AASM Manual. However, the panel note that the clinical benefit of routinely scoring alternating leg muscle activation (ALMA), hypnagogic foot tremor (HFT), hypnagogic foot tremor (HFT) events is limited and is not routine in Australasian laboratories. The ASA/ANZSSA Panel agree with the definitions and rules for the scoring of bruxism as listed in the AASM Manual. However, for routine polysomnography, classification and scoring of bruxism is considered OPTIONAL while reporting the presence of bruxism if

Table 6 Summary of alterations to the AASM Manual Movement Rules recommended by the ASA/ANZSSA Panel

\begin{tabular}{|c|c|c|c|}
\hline \multicolumn{4}{|l|}{ VII. Movement rules } \\
\hline & AASM & ANZSSA/ASA & Difference \\
\hline \multicolumn{4}{|c|}{ A. Technical specifications } \\
\hline Items $1-8$, Notes $1-3$ & & & No change \\
\hline \multicolumn{4}{|c|}{ B. Scoring periodic limb movements in sleep (PLMS) } \\
\hline Items $1-5$, Notes $1-2$ & RECOMMENDED & RECOMMENDED & No change \\
\hline \multicolumn{4}{|c|}{ C. Scoring alternating leg muscle activation (ALMA) } \\
\hline Item 1 , Notes $1-3$ & OPTIONAL & OPTIONAL & No change \\
\hline \multicolumn{4}{|c|}{ D. Scoring hypnagogic foot tremor } \\
\hline Item 1 , Notes $1-2$ & OPTIONAL & OPTIONAL & No change \\
\hline \multicolumn{4}{|c|}{ E. Scoring excessive fragmentary myoclonus } \\
\hline Item 1 , Note $1-3$ & OPTIONAL & OPTIONAL & No change \\
\hline \multicolumn{4}{|l|}{ F. Scoring bruxism } \\
\hline Item 1 & RECOMMENDED & OPTIONAL & Advice change* \\
\hline Notes $1-2$ & & & No change \\
\hline \multicolumn{4}{|c|}{ G. Scoring REM without atonia (RWA) } \\
\hline Item $1-3$, Notes $1-5$ & RECOMMENDED & RECOMMENDED & No change \\
\hline \multicolumn{4}{|c|}{ H. Scoring the PSG features of rhythmic movement disorder } \\
\hline Item 1 & RECOMMENDED & OPTIONAL & Advice change* \\
\hline
\end{tabular}

*For routine polysomnography, scoring is considered OPTIONAL; however, it is RECOMMENDED that its presence be reported if identified. Classification and scoring is RECOMMENDED if the goal of the investigation is to determine the clinical significance of the disorder 
identified is RECOMMENDED. Classification and scoring of bruxism according to the AASM criteria listed is RECOMMENDED if the goal of the investigation is to determine the clinical significance of the disorder. Similarly, the panel agrees with the definitions and rules for the scoring of rhythmic movement disorder; however, its classification and scoring is considered OPTIONAL unless the goal the investigation is to determine the clinical significance of the disorder.

\section{Respiratory rules}

The ASA/ANZSSA Panel recommendations relating to the Respiratory Rules section of the AASM Manual are summarised in Table 7.

\section{A. Technical specifications}

The ASA/ANZSSA Panel agree with the majority of recommended technical specifications for the identification of respiratory events as listed in the AASM Manual.

Snoring (Item A.8) Objective measures of snoring sound level using a calibrated sound level meter are RECOMMENDED. If a sound level meter is used, measurements should be at $1 \mathrm{~m}$ from a patient's mouth set with an "A" weighting to be consistent with international measurement standards (A-weighting and sound recording defined in the international standards for measurement of sound pressure level (IEC 60804, IEC 61672, ANSI/ASA S1.4) which align with human hearing sensitivity). The use of an acoustic sensor (e.g., Microphone), piezoelectric sensor or nasal pressure transducer as RECOMMENDED in the AASM Manual to monitor snoring is considered by the ASA/ANZSSA Panel to be ACCEPTABLE.

\section{B. Measuring event duration}

The ASA/ANZSSA Panel recommend the event duration rules as listed in the AASM Manual. The panel noted that there a minor changes from previous AASM and ASTA/ ASA recommendations regarding hypopnoea start and end point definitions, which are considered further in the Discussion of this document.

Baseline definition (Additional Item B.4) The panel noted that the AASM Manual does not provide a baseline breathing definition in defining apnoeas, hypopnoeas, or event durations. The ASA/ANZSSA Panel recommends baseline breathing is defined as follows:

1. Stable breathing The mean amplitude of stable breathing in the 2 min preceding onset of the event.

2. Unstable breathing The mean amplitude of the three largest breaths immediately preceding onset of the event.

\section{Scoring of apnoeas}

The ASA/ANZSSA Panel recommend using the AASM apnoea definition, and the obstructive and central apnoea classification definitions, without alteration.

Mixed Apnoea Definition (Item C.4) Although the AASM commented in section VIII, C. Note 5 that there was not sufficient evidence to support a specific duration of the central and obstructive components of a mixed apnoea, the ASA/ ANZSSA Panel considered that the inclusion of a minimum duration may assist scorers in differentiating event types and therefore, scoring consistency.

The AASM Manual mixed apnoea definition is RECOMMENDED by the ASA/ANZSSA Panel with the following additional criteria:

For an apnoea to be classified as mixed it must contain a central component with a minimum duration approximating one normal respiratory cycle and it must contain at least one clearly obstructed breath.

Note that while any evidence of obstruction may be considered, by definition, not central, it was considered important to have a minimum duration for scoring consistency.

Events in Wake (Note 3) Note 3 in the Scoring of Apnoeas section specifies that apnoeas and hypopnoeas should be scored and included in the apnoea-hypopnoea index if they start or end in an epoch that is scored as sleep. It remains possible, however, that an event starts and ends in an awake epoch but overlaps a sleep epoch. The ASA/ANZSSA Panel recommend that these events also be scored and included in the AHI, and therefore, Note 3 should be modified (and shortened to remove superfluous text) to read as follows:

If the apnoea or hypopnoea overlaps an epoch that is scored as sleep, then the corresponding respiratory event can be scored and included in the computation of the apnoea-hypopnoea index (AHI). If the apnoea or hypopnoea occurs entirely during epochs scored as wake, it should not be scored or counted towards the AHI. If these occurrences are a prominent feature of the polysomnogram and/or interfere with sleep onset, their presence should be mentioned in the narrative summary of the study.

\section{Scoring of hypopnoeas}

Hypopnoea definition (Item D.1) The ASA/ANZSSA Panel support the use of the RECOMMENDED hypopnoea definition in the AASM Manual (identified as 1A in the AASM Manual). In sum, a hypopnoea is defined as at least a $30 \%$ decrease in a valid hypopnoea sensor signal, where the decrease has a duration of at least $10 \mathrm{~s}$, and is associated with an accompanying EEG arousal or a $3 \%$ or more oxygen desaturation. For consistency between laboratories and scorers the use of hypopnoea definition $1 \mathrm{~B}$, which requires 
Table 7 Summary of alterations to the AASM Manual Respiratory Scoring Rules recommended by the ASA/ANZSSA Panel

VII. Respiratory scoring rules

\begin{tabular}{|c|c|c|c|}
\hline & AASM & ANZSSA/ASA & Difference \\
\hline \multicolumn{4}{|l|}{ A. Technical specifications } \\
\hline Items $1-7,9-10$, Notes $1-4,7$ & & & No change \\
\hline \multicolumn{4}{|l|}{ Item 8: Snoring For monitoring snoring use the following: } \\
\hline a. A sound level meter & Not Included & RECOMMENDED & Addition \\
\hline $\begin{array}{l}\text { b. An acoustic sensor (e.g., microphone), piezoelectric sensor or nasal pressure } \\
\text { transducer }\end{array}$ & RECOMMENDED & ACCEPTABLE & Advice change \\
\hline $\begin{array}{l}\text { Note 5: Snoring Monitoring snoring is recommended as noted in Parameters to } \\
\text { be Reported (II.F) }\end{array}$ & OPTIONAL & RECOMMENDED & Change \\
\hline $\begin{array}{l}\text { Note 6: Hypoventilation Monitoring hypoventilation is recommended if electing } \\
\text { to measure arterial } \mathrm{pCO}_{2} \text { or surrogate }\end{array}$ & OPTIONAL & RECOMMENDED & Change \\
\hline \multicolumn{4}{|l|}{ B. Measuring event duration } \\
\hline Items $1-3$ & & & No change \\
\hline \multicolumn{4}{|l|}{$\begin{array}{l}\text { a. Stable breathing: The mean amplitude of stable breathing in the } 2 \text { min } \\
\text { preceding onset of the event. }\end{array}$} \\
\hline \multicolumn{4}{|l|}{$\begin{array}{l}\text { b. Unstable breathing: The mean amplitude of the three largest breaths imme- } \\
\text { diately preceding onset of the event. }\end{array}$} \\
\hline \multicolumn{4}{|l|}{ C. Scoring of apnoeas } \\
\hline Items $1-3$, Notes $1-2,4$ & & & No change \\
\hline \multicolumn{4}{|l|}{$\begin{array}{l}\text { Item 4: Apnoea classification-mixed Use the AASM mixed apnoea criteria } \\
\text { with the following additional criteria: }\end{array}$} \\
\hline $\begin{array}{l}\text { For an apnoea to be classified as mixed it must contain: } \\
\text { a. A central component with a minimum duration approximating one normal } \\
\text { respiratory cycle, and } \\
\text { b. At least one clearly obstructed breath }\end{array}$ & Not included & RECOMMENDED & Addition \\
\hline $\begin{array}{l}\text { Note 3: Events in Wake If the apnoea or hypopnoea overlaps an epoch that is } \\
\text { scored as sleep, then the corresponding respiratory event can be scored and } \\
\text { included in the computation of the apnoea-hypopnoea index (AHI). However, } \\
\text { if the apnoea or hypopnoea occurs entirely during epochs scored as wake, it } \\
\text { should not be scored or counted towards the AHI. If these occurrences are a } \\
\text { prominent feature of the polysomnogram and/or interfere with sleep onset, } \\
\text { their presence should be mentioned in the narrative summary of the study. }\end{array}$ & & & Wording change \\
\hline Note 5: Apnoea classification-mixed & & & $\begin{array}{l}\text { Deletion (incor- } \\
\text { porated into } \\
\text { 4a above) }\end{array}$ \\
\hline \multicolumn{4}{|l|}{ D. Scoring of hypopnoeas } \\
\hline Items $1 \mathrm{~A}, 2-3$, Notes $1-3$ & & & No change \\
\hline Item 1B. Acceptable hypopnoea definition & ACCEPTABLE & Not Recommended & Advice change \\
\hline \multicolumn{4}{|l|}{ E. Scoring of respiratory effort related arousal } \\
\hline Scoring of RERAs & OPTIONAL & RECOMMENDED & Advice change \\
\hline Item 1. RERA definition & & & No change \\
\hline \multicolumn{4}{|l|}{ F. Scoring hypoventilation } \\
\hline $\begin{array}{l}\text { Monitoring hypoventilation (see } A \text {. Technical Specifications, Note } 6 \text { in this table) } \\
\text { Item 1. Hypoventilation definition, Notes } 1-2\end{array}$ & OPTIONAL* & RECOMMENDED & $\begin{array}{l}\text { Advice change } \\
\text { No change }\end{array}$ \\
\hline \multicolumn{4}{|l|}{ G. Scoring Cheyne-Stokes breathing } \\
\hline $\begin{array}{l}\text { Scoring of Cheyne-Stokes Respiration } \\
\text { Item 1. Cheyne-Stokes definition, Note 1-2 }\end{array}$ & RECOMMENDED & OPTIONAL & $\begin{array}{l}\text { Advice change } \\
\text { No change }\end{array}$ \\
\hline \multicolumn{4}{|l|}{ H. Special Circumstances for Scoring Respiratory Events } \\
\hline Item 1. Respiratory events during PAP, Note 1 & & & No change \\
\hline
\end{tabular}


Table 7 (continued)

VII. Respiratory scoring rules

\begin{tabular}{|c|c|c|c|}
\hline & AASM & ANZSSA/ASA & Difference \\
\hline \multicolumn{4}{|l|}{ I. Measuring oxygen desaturation } \\
\hline $\begin{array}{l}\text { Item 1: Oxygen desaturation events scored must follow a desaturation-resatura- } \\
\text { tion pattern from the pre-event baseline, where baseline is defined as the peak } \\
\text { value immediately prior to the desaturation event, and where there is resatura- } \\
\text { tion of any discernible magnitude. }\end{array}$ & Not included & RECOMMENDED & Addition \\
\hline $\begin{array}{l}\text { Item 2: Desaturation magnitude is the difference between the baseline and the } \\
\text { nadir saturation prior to resaturation }\end{array}$ & Not included & RECOMMENDED & Addition \\
\hline $\begin{array}{l}\text { Note 1: Respiratory event desaturation magnitude For determination of magni- } \\
\text { tude of desaturation associated with a respiratory event, the baseline saturation } \\
\text { is defined as the peak saturation level observed during the respiratory event }\end{array}$ & & & Addition \\
\hline $\begin{array}{l}\text { Note 2: Oximetry lag time Consideration should be given to recognising the } \\
\text { physiological lag time between event and oximetry measurement; typically } \\
\text { around } 25-30 \mathrm{~s} \text { (pathology dependant) }\end{array}$ & & & Addition \\
\hline $\begin{array}{l}\text { Note 3: Wake desaturation Due to oximetry lag time, desaturation events identi- } \\
\text { fied during epochs scored as wake should be counted and included in the } \\
\text { calculation for the ODI. }\end{array}$ & & & Addition \\
\hline
\end{tabular}

*While monitoring of hypoventilation is considered OPTIONAL in the AASM Manual, it is RECOMMENDED that the occurrence of hypoventilation be included in the PSG report if electing to measure the $\mathrm{PCO}_{2}$ or surrogate (II Parameters to be Reported. F. Respiratory Events. Note 4.)

an accompanying $4 \%$ or more oxygen desaturation, is $n o t$ recommended by the ASA/ANZSSA Panel for use in routine PSG scoring, which is a departure from the AASM Manual.

Hypopnoea classification (Item D.2) Consistent with the AASM Manual, the classification of hypopnoeas as central and obstructive event types is considered OPTIONAL. The ASA/ANZSSA Panel also support the hypopnoea classification definitions provided in the AASM Manual; however, it should be noted that hypopnoea classification is not indicated in the majority of patients [18].

\section{E. Scoring of respiratory effort-related arousals}

The ASA/ANZSSA Panel RECOMMENDED respiratory effort-related arousal (RERA) scoring. This is a departure from the AASM Manual, where RERA scoring is considered OPTIONAL. When scoring RERAs the AASM Manual RERA definition is RECOMMENDED.

\section{F. Scoring hypoventilation}

The scoring of hypoventilation is RECOMMENDED by the ASA/ANZSSA Panel (if electing to measure arterial $\mathrm{pCO}_{2}$ or surrogate). The criteria described in the AASM Manual for scoring hypoventilation is RECOMMENDED by the ASA/ ANZSSA Panel. The scoring of hypoventilation requires an increase in the arterial $\mathrm{PaCO}_{2}$ (or surrogate measure) to a value $>55 \mathrm{mmHg}$ for $\geq 10 \mathrm{~min}$, and above a previously stable and reliable baseline average, or if there is a $\geq 10 \mathrm{mmHg}$ increase in arterial $\mathrm{PaCO}_{2}$ (or surrogate measure) during sleep to a value exceeding $50 \mathrm{mmHg}$ for $\geq 10 \mathrm{~min}$. Note the criteria identify scoring hypoventilation during sleep in comparison to an awake supine value. The presence of hypercapnia $\left(\mathrm{PaCO}_{2}>45 \mathrm{mmHg}\right)$ in a patient prior to sleep onset in itself does not warrant the scoring of hypoventilation during sleep if no significant change from baseline is observed.

If $\mathrm{PaCO}_{2}$ values are assumed via a surrogate measure (such as a $\mathrm{TcCO}_{2}$ monitor), then the clinical plausibility of these data should be examined. Methods to do this include comparison to arterial blood gas measurement, or by recalibration of $\mathrm{TcCO}_{2}$ monitor to exclude the possibility of drift or artefact during the recording.

\section{G. Scoring Cheyne-Stokes breathing}

Reporting the occurrence of Cheyne-Stokes breathing, its extent and the scoring criteria described in the AASM Manual is RECOMMENDED by the ASA/ANZSSA Panel, however, as per the Parameters to be Reported section of this document the measurement of the duration of Cheyne-Stokes breathing or number of Cheyne-Stokes breathing episodes is considered OPTIONAL. Scoring of each apnoea/hypopnoea event that occurs as part of a Cheyne-Stokes respiration pattern is RECOMMENDED.

NB: The 'scoring' of hypoventilation and Cheyne-Stokes breathing does not mandate specific episode scoring or statistical calculation to be included in the PSG record but rather a description provided in the laboratory report. 


\section{H. Special circumstances for scoring respiratory events}

The ASA/ANZSSA Panel endorses the recommendations as listed in the AASM Manual.

\section{Measuring oxygen desaturation (additional section)}

Very little detail is provided in the AASM Manual regarding 'scoring' oxygen desaturations. Rule D.1A-B describes the presence of $\mathrm{a} \geq 3 \%$ or $4 \%$ oxygen desaturation from a pre-event baseline for the scoring of hypopnoeas, and, however, provides no further clarification. The lack of an oxygen desaturation definition has been previously noted $[25,26]$. Despite a two device comparison attributing ODI differences to oximeter acquisition and processing factors rather than software ODI calculation algorithms [26], without an oxygen desaturation definition it remains possible for automatic algorithms to differ on features such as $\mathrm{SpO}_{2}$ baseline detection, degree of desaturation and resaturation, and the rate of desaturation and resaturation $[25,26]$. Similarly, desaturations determined by automatic algorithms may differ from human scorers [25].The ASA/ANZSSA Panel by consensus recommend that oxygen desaturation events scored must follow a desaturation-resaturation pattern from the pre-event baseline, where the baseline is defined as the peak value immediately prior to the desaturation event, and where there is resaturation of any discernible magnitude. The magnitude of the desaturation event is the difference between the baseline and the nadir saturation prior to resaturation. For determination of magnitude of desaturation associated with a respiratory event, the baseline saturation is defined as the peak saturation level observed during the respiratory event. Consideration should be given to recognising the physiological lag time between event and oximetry measurement; typically around 25-30 s (pathology dependant). Due to this lag time, desaturation events identified during epochs scored as wake should be counted and included in the calculation for the ODI.

\section{Home Sleep Apnoea Testing (HSAT) rules for adults (Part 1 HSAT utilising respiratory flow and/or effort parameters)}

The ASA/ANZSSA Panel recommendations relating to the Home Sleep Apnoea Testing (HSAT) Rules for Adults section of the AASM Manual are summarised in Table 8.

\section{A. General parameters to be reported}

Identification of the parameters recorded in HSAT studies in the final report is RECOMMENDED by the ASA/ ANZSSA Panel. This includes the type of airflow sensor, if there is respiratory effort recorded, the source of any heart rate parameters (from ECG or from oximeter), if a separate snore channel is used and the presence of oximetry and/ or body position on the recording. If EEG is recorded, this should be clearly identified. If EEG is NOT recorded, the method of identifying the monitoring time should be clearly described.

In addition to the above parameters, clear identification of the sleep service performing the study and the reporting physician (as well as other identifiers outlined in Table 1 for in-laboratory PSG) is also RECOMMENDED.

Due to the wide variety of monitoring equipment used in this category, providing definitions of apnoeas, hypopnoeas and denominator used (i.e., sleep time or monitoring time), is additionally RECOMMENDED for clarity.

In addition to the above parameters, for limited channel studies with less than 3 EEG channels it is RECOMMENDED by the ASA/ANZSSA Panel that the following derivations are used:

1. If only one EEG channel is available record from derivations C4-M1.

2. If more than one EEG channel is available add O2-M1 or alternative F4-M1.

It has been shown that using a single central EEG instead of 3 EEGs as recommended in the AASM Manual results in small shift in sleep stages and no significant difference in arousals scoring statistics or scoring reliability [27].

\section{B. Recording data to be reported if sleep is NOT recorded}

The ASA/ANZSSA Panel agrees with AASM Manual recommendations with the exceptions listed below.

The following parameters are considered OPTIONAL in the AASM Manual, however, are RECOMMENDED by the ASA/ANZSSA Panel, if the appropriate signals are recorded:

1. Reporting the number of obstructive, central, and mixed apnoeas (Item B.6c).

2. Respiratory Event Index (REI) in supine and non-supine positions (Item B.8).

3. Central apnoea index (CAI) (Item B.9).

4. Occurence of snoring (Item B.11).

Note: Scoring of apnoea types may be equivocal unless the monitoring equipment employs both thoracic and abdominal bands.

One measurement of oxygen saturation (Item B.10) is RECOMMENDED for reporting in the AASM Manual (either: (a) ODI; (b) Mean, maximum and minimum $\mathrm{SpO}_{2}$; or (c) \% time below $88 \%$ or other thresholds), although 
Table 8 Summary of alterations to the AASM Manual Home Sleep Apnoea Testing (HSAT) Rules for Adults recommended by the ASA/ ANZSSA Panel

IX. Home sleep apnoea testing (HSAT) rules for adults

AASM ANZSSA/ASA Difference

A. General Parameters to be Reported

Items 1-5, Note 1

Item 6. Body Position

Item 7. Sleep/wake or monitoring time (method for determination)

Item 8. Snoring

Note 2: Alternative airflow sensors: Tidal Volume Sensors (i.e., RIP sum).

Note 3: Measurement of Sleep or Monitoring Time. Sleep should be determined using EEG, EOG, and chin submental EEG recording. If only 1 EEG channel is available record from C4-M1 derivation. If two EEG channels are available add $O 2-M 1$ or alternative F4-M1. The method used to determine monitoring time (MT) should be specified in the report.

Note 4: Respiratory Event Definitions. The respiratory event definitions used and denominator used (i.e., sleep time or monitoring time) should be reported

B. Recording data to be reported if sleep is NOT recorded Items $1-6 \mathrm{~b}, 7$, Note 3 .

Item 6c. Number of obstructive, central and mixed apnoeas

Item 8. Positional REI

Item 9. Central Apnoea Index

Item 10. Oxygen Saturation. A measure of oxygen saturation

Item 10a. Oxygen desaturation index

1. Oxygen desaturation index of $\geq 3 \%$

2. Oxygen desaturation index of $\geq 4 \%$

Item 10b. Oxygen saturation

1. Mean

i. Mean stable baseline prior to sleep onset

ii. Mean during stable NREM sleep

2. Maximum

3. Minimum

Item 10c. Oxygen saturation $\%$ time at or below $88 \%$ or other thresholds

1. $\%$ time at or below $88 \%$

2. \% time at or below other threshold

Item 11. Snoring

Notes 1 and 2. Monitoring time and Respiratory Event Index definitions.

Note 4. Desaturation magnitude for ODI

C. Recording Data to be Reported if Sleep is Recorded

Items 1-6b, 7, Notes 1-2

Item $6 c$. Number of obstructive, central and mixed apnoeas

Item 8. Positional AHI

Item 9. Central Apnoea Index
OPTIONAL

OPTIONAL

OPTIONAL

OPTIONAL

Not included

OPTIONAL

OPTIONAL

OPTIONAL

RECOMMENDED

RECOMMENDED

(1 of $10 a, b$, or $c)$

RECOMMENDED

(1 of $10 a, b$, or c)

RECOMMENDED

Not Included

Not Included

RECOMMENDED

RECOMMENDED

RECOMMENDED

(1 of $10 a, b$, or $c)$

OPTIONAL

OPTIONAL OPTIONAL OPTIONAL
RECOMMENDED

Addition

No change

Advice change

Advice change

Advice change

Advice change

Addition to note

No change

Advice change

Advice change

Advice change

Delete reference to 1 of 3 parameters

Advice change

Advice change

Advice change

Advice change

RECOMMENDED

Addition

Addition

Advice change

No change

Advice change

RECOMMENDED

OPTIONAL

RECOMMENDED* Advice change

Delete reference to reimbursement

Note deletion (incorporated into item 10)

No change

RECOMMENDED

Advice change

RECOMMENDED*

Advice change

RECOMMENDED* 
Table 8 (continued)

IX. Home sleep apnoea testing (HSAT) rules for adults

\begin{tabular}{|c|c|c|c|}
\hline & AASM & ANZSSA/ASA & Difference \\
\hline Item 10. Oxygen Saturation. A measure of oxygen saturation & RECOMMENDED & RECOMMENDED & $\begin{array}{l}\text { Delete reference to } 1 \text { of } 3 \\
\text { parameters }\end{array}$ \\
\hline Item 10a. Oxygen desaturation index & $\begin{array}{l}\text { RECOMMENDED } \\
(1 \text { of } 10 \mathrm{a}, \mathrm{b}, \text { or } \mathrm{c})\end{array}$ & RECOMMENDED & Advice change \\
\hline 1. Oxygen desaturation index of $\geq 3 \%$ & & RECOMMENDED & Advice change \\
\hline 2. Oxygen desaturation index of $\geq 4 \%$ & & OPTIONAL & Advice change \\
\hline Item 10b. Oxygen saturation & $\begin{array}{l}\text { RECOMMENDED } \\
(1 \text { of } 10 a, b, \text { or } c)\end{array}$ & RECOMMENDED & Advice change \\
\hline 1. Mean & RECOMMENDED & & \\
\hline i. Mean stable baseline prior to sleep onset & Not Included & RECOMMENDED & Addition \\
\hline ii. Mean during stable NREM sleep & Not Included & RECOMMENDED & Addition \\
\hline 2. Maximum & RECOMMENDED & OPTIONAL & Advice change \\
\hline 3. Minimum & RECOMMENDED & RECOMMENDED & No change \\
\hline $\begin{array}{l}\text { Item } 10 \mathrm{c} \text {. Oxygen saturation } \% \text { time at or below } 88 \% \text { or other } \\
\text { thresholds }\end{array}$ & $\begin{array}{l}\text { RECOMMENDED } \\
(1 \text { of } 10 \mathrm{a}, \mathrm{b}, \text { or } \mathrm{c})\end{array}$ & & Advice change \\
\hline $1 . \%$ time at or below $88 \%$ & & RECOMMENDED & \\
\hline 2. $\%$ time at or below other threshold & & OPTIONAL & \\
\hline Item 11. Snoring & OPTIONAL & RECOMMENDED* & Advice change \\
\hline \multicolumn{4}{|l|}{ D. Summary statements } \\
\hline Items $1,2 \mathrm{~b}, 3,5 \mathrm{a}-\mathrm{b}$, Notes $1-2$ & & & No change \\
\hline Item 2a: Documentation of repeat investigation & RECOMMENDED & OPTIONAL & Advice change \\
\hline Item 4. Snoring. Occurrence of snoring. & OPTIONAL & RECOMMENDED* & Advice change \\
\hline $\begin{array}{l}\text { Item 5c. Repeat PSG. If study is non-diagnostic, recommend } \\
\text { in-laboratory PSG (if clinically indicated) }\end{array}$ & RECOMMENDED & OPTIONAL & Advice change \\
\hline $\begin{array}{l}\text { Item 7. Practice Management: Recommendation for manage- } \\
\text { ment that meets AASM Clinical Practice Guidelines and } \\
\text { Practice Parameters }\end{array}$ & RECOMMENDED & OPTIONAL & Advice change \\
\hline \multicolumn{4}{|c|}{ E. Technical and digital specifications: HSAT equipment recording features } \\
\hline Items $2,4-8$, Note 2 & & & No change \\
\hline Item 1: Device Approval. Regulatory body approval of device & RECOMMENDED & RECOMMENDED & Delete reference to FDA \\
\hline Item 3: CTP codes & RECOMMENDED & Not included & Item deletion \\
\hline Note 1. CTP codes & & & Note deletion \\
\hline \multicolumn{4}{|l|}{ F. HSAT Respiratory event rules: technical specifications } \\
\hline Items $1 \mathrm{a}, 1 \mathrm{~b}, 2,3,4$, Notes $2-5$ & & & No change \\
\hline Item 1c. Alternative respiratory event sensors & $\begin{array}{l}\text { RECOMMENDED/ } \\
\text { ACCEPTABLE }\end{array}$ & Not recommended & Advice change \\
\hline $\begin{array}{l}\text { Note 1: Flow sensors At least one flow sensor is required. } \\
\text { Ideally both an oronasal thermal sensor and a nasal pressure } \\
\text { transducer should be used to record airflow. }\end{array}$ & & & $\begin{array}{l}\text { Delete reference to alter- } \\
\text { native sensor }\end{array}$ \\
\hline $\begin{array}{l}\text { Note 6: Respiratory effort sensors If respiratory effort is per- } \\
\text { formed one of these technologies should be used. The use of } \\
\text { two belts is preferred; however, one respiratory monitoring } \\
\text { belt is acceptable. }\end{array}$ & & & $\begin{array}{l}\text { Delete reference to } \mathrm{CPT} \\
\text { code }\end{array}$ \\
\hline \multicolumn{4}{|c|}{ G. HSAT respiratory event rules: scoring apnoea utilising respiratory flow and/or effort sensors } \\
\hline Items $1-3$, Notes $1-2,4$ & & & No change \\
\hline \multicolumn{4}{|l|}{$\begin{array}{l}\text { Item 4: Apnoea classification-mixed Use the AASM mixed } \\
\text { apnoea criteria with the following additional criteria is rec- } \\
\text { ommended: }\end{array}$} \\
\hline $\begin{array}{l}\text { a. For an apnoea to be classified as mixed it must contain a } \\
\text { central component with a minimum duration approximat- } \\
\text { ing one normal respiratory cycle and at least one clearly } \\
\text { obstructed breath. }\end{array}$ & Not included & RECOMMENDED & Addition \\
\hline
\end{tabular}


Table 8 (continued)

IX. Home sleep apnoea testing (HSAT) rules for adults

\begin{tabular}{|c|c|c|c|}
\hline & AASM & ANZSSA/ASA & Difference \\
\hline Note 3: Mixed Apnoea Component Duration. & & & $\begin{array}{l}\text { Deletion (incorporated } \\
\text { into item } 4 \mathrm{a} \text { above) }\end{array}$ \\
\hline \multicolumn{4}{|c|}{ H. HSAT Respiratory event rules: scoring hypopnoea utilising respiratory flow and/or effort sensors } \\
\hline Items $1 \mathrm{~A}, 2 \mathrm{~A}$, Notes $1-2$ & & & No change \\
\hline 1B, 2B Alternative hypopnoea definitions & ACCEPTABLE & Not Recommended & Advice change \\
\hline
\end{tabular}

*If appropriate signals recorded

there is acknowledgement that more information is useful to the clinician. Identification of $\geq 3 \%$ (rather than $4 \%$ ) oxygen desaturations for the oxygen desaturation index is RECOMMENDED by the ASA/ANZSSA Panel. The reporting of both minimum $\mathrm{SpO}_{2}$ and oxygen desaturation index (ODI) is also RECOMMENDED. Reporting (1) the average awake $\mathrm{SpO}_{2}$ stable baseline prior to sleep onset, and (2) the average during stable NREM sleep (if recorded), is RECOMMENDED by the ASA/ ANZSSA Panel. The reporting of percentage of time with $\mathrm{SpO}_{2} \leq 88 \%$ is RECOMMENDED and below other thresholds (e.g., $\leq 90 \%$ ) is OPTIONAL. The ability to set oximetry measurement parameters varies and is dependent on manufacturer and model. It is recommended that signal averaging times be set at $2 \mathrm{~s}$, or if not able to be specified, a "short" option be selected if possible.

\section{Recording data to be reported if sleep is recorded}

The ASA/ANZSSA Panel exceptions for Recording Data to be Reported if Sleep is Recorded mirror those in the section Recording Data to be Reported if Sleep is NOT Recorded above.

\section{Summary statements}

The ASA/ANZSSA Panel agree with the Summary Statements as outlined in the AASM Manual with the deviations outlined below.

The following summary statement is considered OPTIONAL in the AASM Manual, however, is RECOMMENDED by the ASA/ANZSSA Panel:

1. Occurrence of snoring (Item D.4).

The following summary statements are RECOM$M E N D E D$ in the AASM Manual, however, are considered OPTIONAL by the ASA/ANZSSA Panel:
1. Documentation of repeat investigation status (Item D.2a).

2. Providing a recommendation for an in-laboratory PSG if the study is non-diagnostic (Item D.5c) (although this is considered desirable).

3. Patient management that meets AASM Clinical Practice Guidelines (Item D.7).

\section{E. Technical and digital specifications: HSAT equipment recording features}

The ASA/ANZSSA Panel agree with the AASM Manual with the deviations outlined below.

FDA approval for device is listed as RECOMMENDED (Item E.1). This is not necessary for Australasia, however, approval from medical device regulators, such as the Therapeutic Goods Association (TGA) in Australia, for the device is required.

Items referring to CPT (Item E.3 and Note 1) are not relevant for Australasia.

\section{F. HSAT respiratory events rules: technical specifications}

The ASA/ANZSSA Panel agree with the AASM Manual with the exceptions outlined below:

1. The alternative sensors listed by the AASM (Item F.1c and Note 1) are not recommended for the primary identification method for detecting airflow.

2. Reference to CPT (Note 6) is not relevant for Australasia.

\section{G. HSAT respiratory event rules: scoring apnoea utilising respiratory flow and/or effort sensors}

The ASA/ANZSSA Panel agree with the AASM Manual with the exception outlined below.

The AASM mixed apnoea definition (Item G.4) should be adopted with the following additional clarifying notes:

For an apnoea to be classified as mixed it must contain: 
a. A central component with a minimum duration approximating one respiratory cycle, and.

b. At least one obstructed breath.

Due to this recommendation Note 3 is no longer relevant.

\section{H. HSAT respiratory event rules: scoring hypopnoea utilising respiratory flow and/or effort sensors}

The ASA/ANZSSA Panel agree with the AASM Manual with the exceptions outlined below.

1. The alternative hypopnoea definitions (Items H.1B and H.2B) are not recommended for use in routine clinical practice to aid consistency across laboratories.

2. For a study without EEG, the recommended definition of hypopnoea will result in systematically less hypopnoeas being scored than if EEG is recorded. To overcome this, a site may use an alternative method of identifying sympathetic activation or arousal as a surrogate for EEG arousal if this method has been validated, and is documented in the explanation of scoring rules used in the report.

\section{Discussion}

This aim of this document was to provide a review of the current AASM Manual, and provide an update to the 2010 ASTA/ASA Commentary that was written in response to the original 2007 AASM Manual for Scoring of Sleep and Related Events. The ASA/ANZSSA Panel conducting the review recognised the significant undertakings in developing the AASM Manual and the value it provides in standardising PSG recording, analysis and reporting, and therefore, a key objective of this review was to align with the AASM wherever possible. However, there were sections of the AASM Manual, where the ASA/ANZSSA Panel considered that clarifications, additions, or alterations were warranted.

\section{Alterations to recommendations}

One of the more notable departures from the AASM Manual, and possibly the most robustly debated within the ASA/ANZSSA Panel, relates to the panel recommendation to exclude arousals scored in awake epochs in the arousal index. The 2007 AASM Manual [1] did not provide guidance as to whether to include EEG arousals in awake epochs in calculating the arousal index. The AASM attempted to clarify this situation with a response to frequently asked questions to the 2007 manual [28] which stated, “... Arousals meeting all scoring criteria but occurring during an awake epoch in the recorded time between "lights out" and "lights on" should be scored and used for computation of the arousal index.". This clarification was carried forward to the next major revision of the AASM Manual and subsequent updates [10]. The 2010 Commentary noted the internal contradiction arising from the requirement to count arousals in awake and sleep epochs, and dividing only by the sleep time for calculating the arousal index. The Commentary also noted the contradictory AASM rule for handling respiratory events scored in wake epochs, which although arbitrary, is at least mathematically consistent. The ASA/ANZSSA Panel recognised that these inconsistencies arise from the application of historical and arbitrary $30 \mathrm{~s}$ epoch boundary scoring during sleep transitions, and therefore, the rational debate and consideration of the limitations of the application of epoch boundaries to sleep staging be reviewed. The obvious advantage of removing an epoch based scoring system is that it will result in far simpler and more consistently applied rules around scoring and classification which will ultimately provide better international standardisation to benefit clinical decisions, research and development of more concordant digital scoring systems. It has been shown that excluding arousals in awake epochs results in a median reduction in arousal index of approximately $5 / \mathrm{h}$, with larger reductions for those with larger AHIs [29].

\section{Clarifications where choices provided}

Providing options for scoring rules and technical specifications undermines the principle of practice standardisation and reproducibility of measurements across services.

One of the key drivers of the 2010 Commentary was to make a single recommendation, where options were provided, in particular regarding the scoring of hypopnoeas. The 2007 AASM Manual [1] provided 'recommended' and an 'alternative' definitions which were fundamentally different (and different from previously recommended criteria). It was recognised that providing a choice of hypopnoea definitions would create confusion [30] and the 2010 ASTA/ASA Commentary [5] provided clarity by recommending the latter definition for use in Australasian laboratories.

The current AASM Manual provides a 'recommended' and an 'acceptable' hypopnoea definition; however, although not specified in the manual, the 'recommend' definition is considered the primary definition and the 'acceptable' definition is provided to facilitate equipment reimbursement in the U.S. setting [18]. Australasian laboratories are not subject to these funding considerations and so the panel specified that only the 'recommended' hypopnoea definition be used in the Australasian setting. Readers should note that the hypopnoea definition recommended in this Commentary (AASM Manual version 2 Recommended [AASMv2]) is slightly different to the 2010 Commentary (AASM Manual version 1 Alternative [AASMv1]) in that the airflow 
reduction requirements are reduced from 50 to $30 \%$. This change would be expected to increase the number of hypopnoeas scored by a small amount. A study examining this change in an Australian clinical cohort [31] found that when comparing AASMv2 to AASMv1 there was a median (interquartile range) increase in AHI of $2.6(0.8,6.8)$ events $/ \mathrm{h}$ $[17 \%(6,33)]$. For AASMv1 and AASMv2, respectively, the median group AHIs were $17.1(7.3,34.5)$ and 21.5 (11.4, 42.1 ), and the percentage contribution of hypopnoeas to the AHI was $94(82,99)$ and $96(86,99)$. A Saudi Arabian study examining a suspected OSA cohort [32] found that when comparing AASMv2 to AASMv1 there was a mean AHI increase of $8.3 / \mathrm{h}$. For AASMv1 and AASMv2, respectively, the median (upper quartile) group AHIs were 18.8 (33.6) and 27.3 (40.0). Although difficult to compare studies, Duce et al. [31] suggested the apparent larger difference compared to their study could be attributed to cohort differences.

The AASM Manual also provides a choice for EEG and EOG electrode placement recommendations. The rationale provided for adopting an alternative bipolar EEG montage in preference to the recommended referential montage was identified in the associated review article for the 2007 AASM Manual [33]. Advantages included allowing for the localisation of potential origin by the site of phase reversal and possible reduction of EMG and ECG artefact; however, this montage would be less familiar to polysomnographers. Duce et al. [34] examined the differences between the recommended and acceptable AASM EEG montages in a prospective, blinded, randomised comparison. No statistically significant differences were observed for PSG statistics; however, the recommended EEG montage had greater interscorer agreement. From this study there appears to be no advantage in using the acceptable over the recommended EEG montage and as such the panel does not recommend its use. Similarly, although the AASM acceptable derivation allows determination of eye movement direction, as mentioned in the 2010 ASTA/ASA commentary, it is unlikely to provide any clinically significant advantage and, therefore, is not recommended in routine clinical practice.

For standardisation the ASA/ANZSSA Panel also recommended reporting a $3 \%$ oxygen desaturation index rather than providing a choice between 3 and $4 \%$. The 3\% desaturation index was chosen to align with the desaturation required for the recommended hypopnoea definition.

\section{Additions}

One area where there was a deliberate omission from the AASM Manual is in the mixed apnoea definition. The AASM Manual does not provide guidance as to the minimum duration of central and obstructive components in a mixed apnoea, citing lack of evidence, however, providing a standard may improve consistency in apnoea classification and, therefore, be valuable in both a research and clinical setting. Thus, although arbitrary, the panel agreed to include minimum durations for central and obstructive components of a mixed apnoea.

Another important area where the ASA/ANZSSA Panel considered necessary to provide additional information, was in defining a baseline for scoring respiratory events. In the AASM Manual the term 'baseline' is used in defining event length, apnoeas and hypopnoeas; however, no definition is provided. This issue was identified in the 2010 Commentary [5] on the 2007 AASM Manual [1], pointing to the AASM frequently asked questions, which provided the following comment: "If there is no clear baseline breathing to measure, due to a high frequency of abnormal respiratory events, then the recovery breaths between the frequent apnoeas or hypopneas would be acceptable to use for an approximate baseline against which to measure the percent of drop for the next reduction in airflow." This statement suggests that during unstable respiration the immediate pre-event breathing amplitude should be considered to be the pre-event baseline; however, in the absence of other guidelines, the ASA/ ANZSSA Panel determined to fall back on Chicago Criteria [4], the only past respiratory event standards which defined a baseline, with a slight modification for simplification. For Chicago Criteria $2 \mathrm{~min}$ of stable breathing was required to determine baseline airflow, and in absence of stable breathing, baseline airflow was considered to be the mean of the largest three breaths in the preceding $2 \mathrm{~min}$. The ASA/ ANZSSA Panel determined that during unstable breathing using the mean amplitude of the three largest breaths immediately preceding onset of the event would simplify baseline determination.

Criteria for defining oxygen desaturation are not only important in calculation of the oxygen desaturation index, but are also important for scoring of respiratory events such as hypopnoeas, where oxygen desaturation is part of the scoring criteria. Despite this oxygen desaturation definitions have been overlooked in standards to date, perhaps due to the reliance on automated calculation in computerised systems. The lack of definition may result in individualised and possibly disparate approaches, and possibly contributes to inconsistency in scoring respiratory events and the AHI. Although arbitrary, the ASA/ANZSSA Panel, therefore, provided an oxygen desaturation definition.

Additional information is provided in this Commentary around scaling of the display of recorded channels, where amplitude decisions are required, for example the amplitude of EEG waves in determining slow wave sleep. Standardisation of channel scaling could theoretically help improve intra- and inter-laboratory agreement in scoring sleep and associated events. 
Additional criteria for classifying arousals in this Commentary are carried forward from the 2010 Commentary. These criteria are useful in determining and standardising if a respiratory event is temporally associated with an arousal, are helpful in distinguishing between respiratory and leg movement arousals, and are thought to provide useful additional clinical information.

Some other areas where the ASA/ANZSSA Panel considered that additions to the AASM Manual were warranted with regards to inclusions in the report include: (1) service, investigation, physician, and patient identifiers, (2) graphical summary, (3) positional, and sleep stage specific (NREM/ REM) respiratory event indices, (4) therapy provided and most effective therapy parameters, (5) $\mathrm{PCO}_{2}$ or surrogate (e.g., $\mathrm{TcCO}_{2}$ ) parameters if recorded, (6) arterial blood gas parameters (if taken), (7) clinical and technical observations that may impact interpretation of the investigation (8) a statement clarifying scoring and analysis criteria used, and, (9) a record of patient perception of sleep quality.

\section{Change of advice}

Although it has been noted that there are relatively few respiratory events scored as RERAs if a definition of hypopnoea is used which requires an associated arousal [18], it remains possible that for some individuals RERAs may be the predominant respiratory event scored, particularly in lean patients [19], and therefore, in these individuals, RERA scoring may add to the clinical picture. For this reason the ASA/ANZSSA Panel has recommended a change of advice regarding the scoring of RERAs, where scoring of RERAs is RECOMMENDED by the ASA/ANZSSA Panel rather than OPTIONAL as indicated in the AASM Manual.

In the same vein, the measurement and reporting of snoring is considered OPTIONAL in the AASM Manual but RECOMMENDED by the ASA/ANZSSA Panel, as it is thought that reporting of snoring aids clinical interpretation. In accordance with the 2010 Commentary, the ASA/ ANZSSA Panel have attempted to standardise the recording and reporting of snoring, with the recommendation to use a sound level meter in preference over other measures of snoring.

\section{No change}

As has been previously stated a key objective of this review was to align with the AASM Manual wherever possible, and therefore, the ASA/ANZSSA Panel agreed with the majority of the manual recommendations. One such area was in the recommendations for measurement of respiratory event length; however, this area may warrant further discussion. The 2007 AASM Manual [1] clarified event duration criteria, defining the start of an event as the "nadir preceding the first breath that is clearly reduced", and the termination of the event as the beginning of the "first breath that approximates the baseline breathing amplitude". There was recognition in the 2010 ASTA/ASA Commentary [5] that the signal used to define "nadir" was not clearly defined. A diagram in the 2007 AASM Manual implied that the nadir was the lowest point of the thermal sensor signal, which corresponded to the zero point of flow on the nasal pressure signal at end expiration/start of inspiration. Clarification was made in the 2010 ASTA/ASA Commentary by explicitly defining the start and end points based on physiology; that is, defined by the respiratory cycle (start of inspiration) rather than the signal, and by clearly stating the corresponding point for each signal. The updated AASM Manual [8] also attempted to clarify this situation by defining the sensors used in determining apnoea and hypopnoea duration and by updating the diagrams illustrating the start and the end of the event. While the illustration for apnoea start and end were unchanged, the illustration for hypopnoea start and end departed slightly from the 2007 manual illustration and 2010 commentary recommendations. Instead of the mid-point of the nasal pressure signal the new diagram suggests that lowest point of the nasal pressure should be used to determine the start and end of a hypopnoea, which corresponds to mid-expiration in the respiratory cycle. While the panel questioned the validity of using a start/end point during mid-expiration it agreed not to depart from the AASM Manual, as it considered the rule relatively simple to apply and the change of little consequence.

\section{Conclusion}

The aim of this document was to provide a commentary on the AASM Manual for Scoring of Sleep and Associated Events in an Australasian context. A panel of Australasian sleep professionals developed the commentary, with understanding and acknowledgement of the significant advancement in the standardisation of polysomnography recording, analysis, and reporting provided by the AASM Manual. However, there were sections of the AASM Manual, where the panel determined that there were clarifications, additions, or alterations required. The panel anticipates that the recommendations provided in this document will improve standardisation across Australasian sleep services; however, many of the recommendations are also relevant in a global setting and should be considered for inclusion in future updates of the AASM Manual.

Acknowledgements The panel would like to acknowledge Tom Churchward and John Wheatley for review of manuscript content.

Author contributions This commentary was developed via a panel of Australasian Sleep Association (ASA) Clinical Committee members 
and Australian and New Zealand Sleep Science Association (ANZSSA, formerly Australasian Sleep Technologists Association) members, chaired by Greg Jorgensen. All authors were members of the panel and contributed to the review and recommendations contained within. GJ authored the first version of this document, and WR carried out subsequent major revision and preparation for publication, with input from other authors. All authors approved the final version of the manuscript.

Funding No funding was provided for the development of this manuscript.

\section{Compliance with ethical standards}

Conflict of interest On behalf of all authors, the corresponding author states that there is no conflict of interest.

Open Access This article is licensed under a Creative Commons Attribution 4.0 International License, which permits use, sharing, adaptation, distribution and reproduction in any medium or format, as long as you give appropriate credit to the original author(s) and the source, provide a link to the Creative Commons licence, and indicate if changes were made. The images or other third party material in this article are included in the article's Creative Commons licence, unless indicated otherwise in a credit line to the material. If material is not included in the article's Creative Commons licence and your intended use is not permitted by statutory regulation or exceeds the permitted use, you will need to obtain permission directly from the copyright holder. To view a copy of this licence, visit http://creativecommons.org/licenses/by/4.0/.

\section{References}

1. Iber C, Ancoli-Israel S, Chesson A, Quan S, for the American Academy of Sleep Medicine. The AASM manual for the scoring of sleep and associated events: rules, terminology and technical specifications. 1st ed. American Academy of Sleep Medicine: Westchester; 2007.

2. Rechtschaffen A, Kales A. A manual of standardised terminology, techniques and scoring system for sleep stages of human subjects. Los Angeles: Brain Research Institute; 1968.

3. Bonnet M, Carley D, Carskadon M, Easton P, Guilleminault C, Harper R, et al. EEG arousals: scoring rules and examples: a preliminary report from the Sleep Disorders Atlas Task Force of the American Sleep Disorders Association. Sleep. 1992;15(2):173-84.

4. Flemons WW, Buysse D, Redline S, Oack A, Strohl K, Wheatley $\mathrm{J}$, et al. Sleep-related breathing disorders in adults: recommendations for syndrome definition and measurement techniques in clinical research. The Report of an American Academy of Sleep Medicine Task Force. Sleep. 1999;22(5):667-89.

5. Thornton AT, Ruehland WR, Duce B, Wheatley JR, Douglas J, Rochford PD, et al. ASTA/ASA Commentary on AASM Manual for the Scoring of Sleep and Associated Events. 2010. https://sleep .org.au/Public/Resource-Centre/F-Sleep-docs/ASTA-ASA-comm. aspx. Accessed 19 Mar 2019

6. Grigg-Damberger MM. The AASM Scoring Manual four years later. J Clin Sleep Med. 2012;8(3):323-32.

7. Grigg-Damberger MM. The AASM scoring manual: a critical appraisal. Curr Opin Pulm Med. 2009;15(6):540-9. https://doi. org/10.1097/MCP.0b013e328331a2bf.

8. Berry R, Brooks R, Gamaldo C, Harding S, Marcus C, Vaughn $\mathrm{B}$, et al. The AASM Manual for the Scoring of Sleep and Associated Events: Rules, Terminology and Technical Specifications,
Version 2.0. Darien, Illinois: American Academy of Sleep Medicine; 2012. http://www.aasmnet.org/scoringmanual/. Accessed 27 Aug 2016

9. Douglas JA, Chai-Coetzer CL, McEvoy D, Naughton MT, Neill AM, Rochford P, et al. Guidelines for sleep studies in adults-a position statement of the Australasian Sleep Association. Sleep Med. 2017;36(Supplement 1):S2-22.

10. Berry RB, Quan SF, Abreu AR, Bibbs ML, DelRosso L, Harding $\mathrm{SM}$, et al. The AASM manual for the scoring of sleep and associated events: rules, terminology and technical specifications, version 2.6. Darien, Illinois: American Academy of Sleep Medicine; 2020. http://www.aasmnet.org/scoringmanual/. Accessed 13 Jan 2020

11. Aldrich M. Diagnostic value of video-EEG polysomnography. Neurology. 1991;41(7):1060.

12. Drakatos P, Higgins SE, Kosky CA, Muza RT, Williams AJ. The value of video polysomnography in the assessment of intermittent obstructive sleep apnea. Am J Respir Crit Care Med. 2013;187(10):e18-20.

13. Mador MJ, Kufel TJ, Magalang UJ, Rajesh SK, Watwe V, Grant BJB. Prevalence of positional sleep apnea in patients undergoing polysomnography. Chest. 2005;128(4):2130-7.

14. Barnes H, Edwards BA, Joosten SA, Naughton MT, Hamilton GS, Dabscheck E. Positional modification techniques for supine obstructive sleep apnea: a systematic review and meta-analysis. Sleep Med Rev. 2017;36:107-15.

15. Haba-Rubio J, Janssens J, Rochat T, Sforza E. Rapid eye movement-related disordered breathing-clinical and polysomnographic features. Chest. 2005;128(5):3350.

16. Su CS, Liu KT, Panjapornpon K, Andrews N, Foldvary-Schaefer N. Functional outcomes in patients with REM-related obstructive sleep apnea treated with positive airway pressure therapy. J Clin Sleep Med. 2012;8(3):243-7.

17. Redline S, Budhiraja R, Kapur V, Marcus CL, Mateika JH, Mehra $\mathrm{R}$, et al. The scoring of respiratory events in sleep: reliability and validity. J Clin Sleep Med. 2007;3(2):169-200.

18. Berry R, Budhiraja R, Gottlieb DJ, Gozal D, Iber C, Kapur VK, et al. Rules for scoring respiratory events in sleep: update of the 2007 AASM Manual for the scoring of sleep and associated events: deliberations of the Sleep Apnea Definitions Task Force of the American Academy of Sleep Medicine. J Clin Sleep Med. 2012;8(5):597-619.

19. Guilleminault C, Stoohs R, Clerk A, Cetel M, Maistros P. A cause of excessive daytime sleepiness. The upper airway resistance syndrome. Chest. 1993;104(3):781-7.

20. Guilleminault C, Black JE, Palombini L, Ohayon M. A clinical investigation of obstructive sleep apnea syndrome (OSAS) and upper airway resistance syndrome (UARS) patients. Sleep Med. 2000;1(1):51-6.

21. Beasley R, Chien J, Douglas J, Eastlake L, Farah C, King G, et al. Thoracic Society of Australia and New Zealand oxygen guidelines for acute oxygen use in adults: 'Swimming between the flags'. Respirology. 2015;20(8):1182-91.

22. Westreich R, Gozlan-Talmor A, Geva-Robinson S, SchlaefferYosef T, Slutsky T, Chen-Hendel E, et al. The presence of snoring as well as its intensity is underreported by women. J Clin Sleep Med. 2019;15(3):471-6.

23. Berlowitz DJ, Spong J, O’Donoghue FJ, Pierce RJ, Brown DJ, Campbell DA, et al. Transcutaneous measurement of carbon dioxide tension during extended monitoring: evaluation of accuracy and stability, and an algorithm for correcting calibration drift. Respir Care. 2011;56(4):442-8.

24. Smith SW. The scientist and engineer's guide to digital signal processing. 1997. http://www.dspguide.com/pdfbook.htm. Accessed June 2018 
25. Churchward T, Miles J, Sparks I, Ruehland W, Rochford P. Manual versus automated detection of oxygen desaturation index. Sleep Biol Rhythms. 2010;8(S1):A51.

26. Ng Y, Joosten SA, Edwards BA, Turton A, Romios H, Samarasinghe $\mathrm{T}$, et al. Oxygen desaturation index differs significantly between types of sleep software. J Clin Sleep Med. 2017;13(4):599-605.

27. Ruehland WR, O'Donoghue FJ, Pierce RJ, Thornton AT, Singh P, Copland JM, et al. The 2007 AASM recommendations for EEG electrode placement in polysomnography: impact on sleep and cortical arousal scoring. Sleep. 2011;34(1):73-81.

28. The American Academy of Sleep Medicine. AASM-scoring manual frequently asked questions. Darien, Illinois: American Academy of Sleep Medicine; 2008. http://www.aasmnet.org/ SMFAQs.aspx. Accessed 18 Apr 2008

29. Ruehland W, Churchward T, Tolson J, Melehan K, Wilson D. The impact of excluding arousals scored in awake epochs of polysomnography on the arousal index. J Sleep Res. 2019;28(S1):53.

30. Ruehland WR, Rochford PD, O'Donoghue FJ, Pierce RJ, Singh P, Thornton AT. The new AASM criteria for scoring hypopneas: impact on the apnea hypopnea index. Sleep. 2009;32(2):150-7.
31. Duce B, Milosavljevic J, Hukins C. The 2012 AASM respiratory event criteria increase the incidence of hypopneas in an adult sleep center population. J Clin Sleep Med. 2015;11(12):1425-31.

32. BaHammam AS, Obeidat A, Barataman K, Bahammam SA, Olaish AH, Sharif MM. A comparison between the AASM 2012 and 2007 definitions for detecting hypopnea. Sleep Breath. 2014;18(4):767-73.

33. Silber MH, Ancoli-Israel S, Bonnet MH, Chokroverty S, GriggDamberger MM, Hirshkowitz M, et al. The visual scoring of sleep in adults. J Clin Sleep Med. 2007;3(2):121-31.

34. Duce B, Rego C, Milosavljevic J, Hukins C. The AASM recommended and acceptable EEG montages are comparable for the staging of sleep and scoring of EEG arousals. J Clin Sleep Med. 2014;10(7):803-9.

Publisher's Note Springer Nature remains neutral with regard to jurisdictional claims in published maps and institutional affiliations. 